\title{
From Comfort Zone to Reality: A Community Engagement to Enhance Student's Academic Performance
}

\author{
Welcome Mswazi Kubeka \\ Additional information is available at the end of the chapter
}

http://dx.doi.org/10.5772/intechopen.76010

\begin{abstract}
The involvement of universities in communities is not a new phenomenon, as they have been known to engage their surrounding communities by expanding knowledge beyond the institutional confinements. This paper reports on the feedback received from the learners detailing their perceptions of the community engagement work done by the UJ Learning Development through academic study skills workshops to improve the learners' academic performance. A quantitative approach was used to collect data by means of a feedback questionnaire. The feedback questionnaire was divided into two parts, namely, the biographical details of the participants and the participants' perceptions of the academic study skills workshops they had attended. The questionnaire was administered to a target population of 302 learners at Ikamva Youth (Ivory Park and Ebony Park branches). Sixty participants were randomly selected from both grade 10 and grade 11 strata; in the last stratum, all the thirty grade 12 participants were considered. The main findings are that the majority of participants indicated that they do apply the skills learnt from the workshops while learning material and content from other subjects. They also indicated that their academic performance had improved from the time they started applying the study skills.
\end{abstract}

Keywords: community engagement, academic performance, study skills, study habits, integrated and embedded skills

\section{Introduction}

Community engagement is one of the pillars of the vision of the University of Johannesburg (UJ) as a transformed higher education institution. The involvement of universities in communities 
is not a new phenomenon since they have been known in engaging with their communities by expanding knowledge beyond the confinement of institutions. Osman and Peterson [1] state that universities should move away from their ivory tower image to engage the communities in order to promote academic programmes, which are responsive to the needs of the surrounding communities. UJ articulated its community engagement in terms of service learning, community-based research, organised outreach and experiential learning. According to the relevant UJ Policy [2], these community engagement initiatives are clarified as follows:

- Service learning - a form of community engagement, which entails teaching and learning, which is directed at specific community needs, is curriculated and awards academic credits to students [2].

- Community-based research - a form of community engagement that focuses on research projects in order to make a significant contribution to a community in the form of services, products and/or new knowledge and skills transfer.

- Organised outreach-activities, which are organised by the students or employees of the institution and conducted outside the academic programmes, with the purpose of addressing the interests and needs of the communities [2].

- Experiential learning - a process and a method of education through types of learning activities, which afford the students an opportunity to engage directly with the phenomenon being studied and to reflect on the experience of such engagement.

For the purpose of this paper, the concept of community engagement was used to encompass all the forms mentioned above. The University of Johannesburg sees community engagement as initiatives and processes in which the knowledge capital and resources of the institution are utilised in partnerships with the community in order to address the development needs of the target community [2]. Such initiatives and processes are offered to the interest groups by the institution with no financial request [2].

Ikamva Youth (IY) is a non-profit organisation (NPO) established in 2003 with branches in five provinces in South Africa. It operates in the Western Cape, Gauteng, KwaZulu-Natal, NorthWest and Eastern Cape. This NPO focuses on learners from disadvantaged communities with the sole purpose of equipping them with the knowledge, skills, networks and resources needed to access tertiary education and/or potential opportunities of employment after matriculation [3]. It is aimed at increasing the population's skill level, growing the national knowledge base and replicating the success of this programme in other communities [3]. The learners enrol at IY when they are promoted to grades between 9 and 12 [4]. The number of grade 12 learners, who can access higher education institutions and/or employment-based learning opportunities after matriculation, is a factor, which determines the success of the programme [3, 4, 43].

The IY model draws its volunteers from a growing pool of students from the nearby universities and professionals from local companies [4]. Its sustainability is driven by former learners studying at the surrounding institutions of higher education, who return to the organisation to offer tutoring [4]. This model provides the additional advantage of allowing former IY learners to be agents of change and transition from beneficiary to benefactor [3]. In South 
Africa, the majority of youth encounter several socioeconomic obstacles, which perpetuate disadvantage and exacerbate the situation in most township and informal settlements, where schools produce substandard academic performance for most learners. The IY offers seven programmes, namely, supplementary tutoring; homework sessions; career guidance; mentoring; computer literacy and access; media, image and expression; and health and leadership [3]. The organisation comprises three branches in the Gauteng Province, respectively, in Midrand, Ebony Park and Ivory Park. It also has a branch in Mamelodi, City of Tshwane.

UJ launched this partnership with both Ivory Park and Ebony Park branches of Ikamva Youth as a contribution to efforts geared towards addressing the needs of the twenty-first century youth by empowering the learners in these centres with academic study skills. A detailed schedule was developed, and an agreement was entered into with the coordinators of the two branches to facilitate study skills workshops, such as setting goals, time management, note making and examination preparation strategies for the grade 10-12 students on weekends (Saturdays).

In South Africa, a great deal of studies have been conducted on community engagement, but few locally based studies have been conducted on how the acquisition of academic study skills could contribute to learner academic performance. The study conducted by Garikai [5] concluded that the determinant of academic performance for students is a factor of variables such as the distance travelled to school, student gender, age, language spoken at home, education status of parents and nutrition levels.

The research question, which guided the research design and the qualitative analysis, is as follows: What are the learners' perceptions of the contribution of academic study skills towards their academic performance. The purpose of this paper is to report on the feedback received from the learners in order to positively influence or improve future community engagement initiatives.

\section{Literature review}

The Higher Education Quality Committee (HEQC) of South Africa defines community engagement as an initiative and process through which the expertise of institutions in the areas of teaching and research is applied to address issues relevant to the communities [6]. Community engagement finds expression varying forms, ranging from informal and relatively unstructured activities to formal and structured academic programmes addressing particular needs [6]. According to Wright et al. [7], community engagement is a collaboration between institutions of higher education and their larger communities for mutually beneficial exchange of knowledge and resources in a context of partnership and reciprocity. The definition of community engagement as provided by Dharamsi et al. [8] describes activities undertaken with community members, which result in greater social responsibility towards and awareness of the needs of vulnerable populations. In the South African context, the vulnerable people can be said to be those who are less disadvantaged and residing in black townships and informal settlements. 
There is a great deal of potential through community engagement due to its ability to create and sustain change for the greater good [9]. As a result, it is imperative to develop community engagement programmes, which will benefit the disadvantaged communities at large. Sustainable community engagement relationships should be built with these communities.

In this paper, the concept of study habits encompasses subtopics such as study attitudes, study methods and study skills. The following is a brief description of the concepts study habits, study attitudes, study methods and study skills:

- Study habits denote the degree to which the student engages in regular acts of studying characterised by appropriate study routines occurring in an environment, which is conducive to studying [10]. Whereas [11] see study habits as learning tendencies, which enable students to work privately.

- Study attitudes according to [12] refer to predispositions, which students have developed towards private reading, with time, and offer great possibilities for successful achievement in studies.

- Study method is the knowledge and application of effective study skills or techniques by students [10].

- Study skills are the potential for action, while study behaviours are the action [13].

For the purpose of this study, the focus is on study skills. Different studies have been conducted on the correlation of study habits and academic achievement. A study conducted by Anwar [14] found that the academic achievement of the students with good study habits differed significantly from those with bad habits. Another study conducted by Tinto [15] also found that good study habit was associated with high-level academic achievement and that boys had better study habits than girls. In their studies, [16] also found that day scholars have better study habits than hostel dwellers, while female students have more concentration span, better study habits and higher academic achievement than their male counterparts.

The notion of 'one size fits all' is no longer applicable as far as learner academic study skills development is concerned due to the learning style diversity. There are various approaches to the development of academic study skills, including:

- Embedding, where there is no direct reference to the development of transferable skills, and the emphasis is solely on the development of technical 'know-how'.

- Bolt on, in which skills are developed independently from the core discipline to enable the explicit development of the students' transferable skills.

- Integrated academic study skills are developed and taught explicitly within the core discipline with an emphasis on the technical abilities of the learners to apply the transferable skills [17].

If the provision of skills development is to incorporate knowledge and understanding, analysis, creativity and evaluation, then integrating academic study skills into learners study 
material is the only viable option [18]. Cottrell [19] argues that learning development and skills enhancement do not thrive, when they are divorced from the students' overall teaching and learning experience. Furthermore, Burns and Sinfield [20] are of the opinion that, for skills teaching to be effective, it must be well anchored and contextualised within the subject specialism. These points are also supported by [21], who argues that students benefit from the integration of learning development strategies into their core curriculum; hence embedding skills ensure that there is a meaningful application in students' relevant subjects. Study skills may be most beneficial when instruction occurs within the content area classroom [22].

In this study, the researcher integrated the study skills into learners' content areas by applying [23] the following principles: (a) modelling the strategy, (b) explaining why the strategy works, (c) showing how the strategy may be used in other contexts and (d) providing opportunities for practice. For instance, in the workshop session on 'note making', the researcher taught the learners the skill of making their notes in various ways, including mind mapping and annotating. In these instances, the researcher used the students' study material and provided them with an opportunity to practice these skills. This is in line with the views that teaching active note making to students may enable them to gain a voice and take ownership of ideas and concepts in powerful ways [20, 24].

As indicated, though the knowledge and application of effective study skills and study behaviours have long been associated with overall academic achievement, these skills and behaviours often need to be explicitly taught to students [25]. Some authors argue that when taught to students, the following academic skills can improve their academic performance in several ways:

- Goal setting-goals direct the student's attention to the task. They also keep the student focused. Goals increase persistence [26].

- Time management-students will be able to manage their time wisely and overcome procrastination and not wait until the last minute to work. They will also be able to prioritise tasks and time [27].

- Note making - students will be able to find the main idea of a passage [28].

- Examination preparation-the students will develop an awareness of the types of questions often used in examination papers, which will help them to prepare adequately.

The partnership with the Ikamva Youth (Ivory Park and Ebony Park branches) is based on Freire's [29] theoretical framework, which stipulates that dialogue is the primordial concept and a point of departure from which an examination of the process of achieving authentic partnership can be conducted. In a dialogue approach, everyone participates as equals. It is based on the understanding that the designed academic study skills schedule intended for learners was a negotiated agreement with all partners involved.

This study is also based on Tintos' theory of student departure, which emphasises that the key to college students' persistence resides in the integration of both the students' academic performance and their social lives $[15,42]$. In cases where students are unable to connect 
with other academic or social subsystems, there is a highly likelihood that such students may leave the institution [14]. In expanding this theory during the Regional Symposia on Student Success held in South Africa, Tinto stated that access to higher education without support is not opportunity. Tinto further mentioned that any improvement in the student success rates requires intentional and structured action, which is systematic and coordinated in nature and involves many people across campus [30].

\section{Research methodology}

The study used a quantitative approach, and data was collected through a feedback questionnaire or form. Part one of the feedback questionnaire gathered data on learner's biographical details, including gender, age and grade. Part two of the feedback questionnaire requested learners to:

- Indicate the workshops they have attended.

- Indicate which skills they have applied among those that they had learnt in the workshops.

- Indicate if their academic performance has improved from the moment they started applying the skills learnt in the workshop.

- Give their views on the workshops.

The feedback questionnaire was administered to a target population of 302 learners at Ikamva Youth (Ivory Park and Ebony Park branches). Before administering the feedback questionnaire to the sample, a pilot study was conducted with a selected number of students who do not form part of the target population, in order to measure its quality and appropriateness, and redesign it for clarity. This pilot sample of students did not experience any difficulties in understanding the questions.

A stratified random sampling technique was used to select the sample in such a way that identified subgroups (according to grades) were represented in the sample [31]. Sixty participants were randomly selected from the grade 10 and grade 11 stratum, except for the last stratum (grade 12 learners), where only thirty respondents were represented. There were therefore 150 randomly selected participants in total (50\% of the total population of 302).

According to Opie [32] ethics has to do with the prevention of any harm or wrongdoing against others and the promotion of good faith, respect and fairness. The anonymity of all participants was upheld in the data collection instrument, and the researcher informed the respondents that they could withdraw participation at any time without penalty and that their information would remain confidential. Since the participants' were minors, consent forms were completed and signed by their parents or guardians, who gave permission for the learners' participation. Permission to conduct the study was also granted by the Ikamva Youth (Ebony Park and Ivory Park branches). 


\section{Results and discussions}

This section presents the participants' biographical detail as well as their perceptions about the contribution of academic study skills towards their academic performance. Part one (biographical information) and part two (three closed-ended questions) are presented descriptively in the form of frequencies count, percentages and mean. The open-ended question in part two was qualitatively presented.

Part one: biographical information presentation

The profiles of the participants in terms of gender, current grades and their ages are presented below.

The data presented in Table 1 shows that most learners who participated in this study are females (57\%) and the males (43\%) are few. These results are in line with the fact that there are more females than males in South Africa. Fifty percent of the respondents are in grade 11, and only $10 \%$ are in grade 12 . The profile of the respondents also shows that the majority $(53 \%)$ of them are within the age of 14 and 16 years. The concern is that some of the participants are above the age of 19 years (7\%). In South Africa, learners are expected to start their basic schooling at the age of seven in order to complete their final grade 12 at the age of 18 [33].

Part two: Learners' results on the workshops

In part two, three (3) closed-ended questions and one (1) open-ended question were asked.

\subsection{Close-ended questions}

The purpose of Question 1 in Table 2 was to determine the workshops that each of the participants attended. The following are the close-ended question results:

The participants' responses in Table 2 show that the least attended workshop session was on goal setting $(16 \%)$. This signifies that learners are not aware that goals are the building blocks

\begin{tabular}{llll}
\hline Biographical variable & Description & Frequency & Percentage \\
\hline Gender & Male & 131 & 43 \\
Learners' grades & Female & 171 & 57 \\
& 10 & 120 & 40 \\
Participants' ages & 11 & 152 & 50 \\
& 12 & 30 & 10 \\
& $14-16$ years & 160 & 53 \\
& $17-18$ years & 122 & 40 \\
\hline
\end{tabular}

Table 1. Biographical details of the participants. 


\begin{tabular}{lllll}
\hline Question 1: Which of the following workshops have you attended? & & & \\
\hline Workshop & Frequency & Percentage & Mean & Remarks \\
\hline Goal setting & 24 & 16 & 6 & Accepted \\
Time management & 34 & 23 & 8.5 & Accepted \\
Note making & 32 & 21 & 8 & Accepted \\
Examination preparations & 60 & 40 & 15 & Accepted \\
Total & $\mathbf{1 5 0}$ & $\mathbf{1 0 0}$ & &
\end{tabular}

Table 2. Indication of the workshops attended by the participants. Mean $\geq 2.50$ is accepted and Mean $<2.50$ is rejected.

of success and learning, as they may assist a learner to stay focused and accomplish his/her personal and academic desires. Locke and Latham [26] state that goals direct our attention to the task at hand. The researcher is also of the opinion that goals are guides for action and may serve as a source of motivation.

The data also shows that participants are struggling with time management, the second workshop with the least attendance (21\%). Time management is one of the most determinant factors of student academic success. The researcher has the opinion that unnecessary disruptions such as being in the company of friends all the time could be avoided if learners were able to allocate sufficient and realistic time to study. One of the benefits that learners will enjoy when they are able to manage their time will be being able to overcome procrastination and avoid waiting until the last minute [27]. The highest attended workshop session was on examination preparation with $40 \%$ of participants. The researcher has the opinion that if learners are well prepared for examinations, they will be able to manage the feelings of anxiety and tension, which learners normally experience before and after examinations.

Authors such as Turner et al. [34] posit that examination anxiety and tension could lead to the development of interfering thoughts, which could undermine a learners' ability to recall previously learned material and prevent learners from focusing on the examination tasks at hand. Deb et al. [35] confirm that the association between examination-related anxiety and tension with psychiatric problems. He notes that because the coping abilities of learners vary from one learner to another, learners with poor coping capabilities become prone to anxiety and fear of academic failure. The two models, which explain the negative effects of anxiety, are the Interference model and the learning deficit model. According to Sansgiry et al. [36], in the interference model, anxious learners are distracted due to task irrelevant to and negative thoughts about examinations, whereas the learning deficit model proposes that it is the learners' ineffective study habits during examination preparation that causes high levels of anxiety.

Question two in Table 3 was asked in order to find out if the learners are applying the skills learned during the workshops in their respective learning subjects.

The results presented in Table 3 give rise to a concern that most participants' indicated to have applied the skills learnt in two of the workshops sessions, namely, examination preparation $(45 \%)$ and time management $(27 \%)$. The concern is based on the researchers' opinion that 


\begin{tabular}{lllll}
\hline Question 2: Which of the skills you learnt in the workshop have you applied? & & \\
\hline Workshop & Frequency & Percentage & Mean & Remarks \\
\hline Goal setting & 18 & 12 & 4.5 & Accepted \\
Time management & 40 & 27 & 10 & Accepted \\
Note making & 24 & 16 & 6 & Accepted \\
Examination preparations & 68 & 45 & 15 & Accepted \\
Total & $\mathbf{1 5 0}$ & $\mathbf{1 0 0}$ & &
\end{tabular}

Table 3. Application of the skills learned. Mean $\geq 2.50$ is accepted and Mean $<2.50$ is rejected.

the application of all the presented academic study skills by learners in their learning content contributes to positive academic success. The researcher's position is supported by [24], who argues that the knowledge and application of effective study skill and study behaviours have long been associated with overall academic achievement. These effective study skills and study behaviours, however, often need to be taught explicitly to students.

The purpose of Question 3 in Table 4 was to determine whether the participants' performance has improved from the time they started applying the skills learnt in the workshops.

Table 4 shows that the majority $(87 \%)$ of the participants are of the opinion that their academic performance has improved because they applied the skills learned in the workshops in their academic work. The researcher agrees with the assumption that because learner academic performance is a factor of various variables, other academic support inputs could be added as a contributory factor. In his study, Garikai [5] concluded that the determinant factor of academic performance for students is a factor of variables such as the distance travelled to school, age of students, sex, language spoken at home, education status of parents and nutrition levels. This is summarised in this empirical model, which stipulated as, PERF $=f$ AGE, SEX, DIST, LANG, PARENT, NUTR\}. In as much as empirical studies show that learners' academic performance is a factor of various variables, the researcher concluded based on the positive feedback given by the learners who participated in this academic support sessions that academic support also contributed to their academic performance. Hence, it is justifiable for the researcher to argue that this empirical model can be expanded to include academic support (AS), to read as, PERF $=f\{$ AGE, SEX, DIST, LANG, PARENT, NUTR, AS $\}$.

\begin{tabular}{lllll}
\hline \multicolumn{4}{l}{ Question 3: Has your academic performance improved since applying the skills learned in the workshops? } \\
\hline Scale & Frequency & Percentage & Mean & Remarks \\
\hline Yes & 130 & 87 & 65 & Acceptable \\
No & 20 & 13 & 10 & Acceptable \\
Total & $\mathbf{1 5 0}$ & $\mathbf{1 0 0}$ & & \\
\hline
\end{tabular}

Table 4. Indication of learners' academic improvement. Mean $\geq 2.50$ is accepted and Mean $<2.50$ is rejected. 
Embedding academic study skills in the learners learning content may also contribute positively to their academic performance. It is against this background that [19] posits that skill enhancement initiatives do not thrive if they are divorced from the students' overall teaching and learning experience. Hence, for skills teaching to be effective, it must be well anchored and contextualised within the subject. The researcher is also of the opinion that students who possess strong academic study skills are likely to achieve academically.

\subsection{Open-ended questions}

The researcher used the following procedures in analysing the open-ended question responses. After collecting the data gathered from the participants, the researcher organised and worked to make sense of the data in three stages, namely, data condensation, data display and draw conclusion [37].

\section{Stage 1: data condensation}

According to Miles and Huberman [37], data condensation is a process through which data is selected, summarised, labelled and coded. Data condensation enabled the researcher to select the data chunks to code and labels, which are suitable for the data, developing categories and themes in the process. As a researcher, I read, further read and re-read the transcripts until the data have been fully absorbed.

Thereafter, the data was coded manually. Saldanha [38] argues that manual coding is regarded as a precoding strategy which is suitable for novice coders.

\section{Stage 2: data display}

Data was displayed to indicate the relationship between concepts and coded information.

\section{Stage 3: draw conclusion}

Based on the themes that emerged, conclusions were drawn to interpret the respondents' responses.

The themes that emerged based on the participants' responses are presented below verbatim, namely:

\section{Theme 1: ability to manage time}

The participants' responses foregrounded time management as one of the most important skills. The participants were able to see the benefits of managing time, as shown in the following responses: '... this workshops help us a lot because now I can manage my time'. Another participant added ' ... they helped me a lot and now I know that I should be committed in my school work and avoid to waste my time with friend...'. Another participant stated, 'they do help, but the problem is that I am just being lazy and I do not do my school work on time ...'.

It can be seen from these responses that the participants' perceptions of the workshops are that they are beneficial and can help them use their time wisely. This is supported by Bailey and Onwuegbuzie [27] who confirm that the benefit of time management is that learners will know how to prioritise time. 


\section{Theme 2: confidence in taking examinations}

Another theme that emerged from the data is 'confidence in taking examinations'. The participants' responses indicate that exam preparation is also a crucial academic study skill, which learners should be taught. From the verbatim responses from some of the participants' responses, there is a perception from participants that one of the benefits of examination preparations is that it could boost their confidence in taking examination. One of the participants stated, 'the workshop have helped me with the method on how to approach exams'. Another participant indicated that 'when answering questions in the exams ... I did not panic so I make less mistakes'. Sharing their positive views about this workshops, another participant pointed out that 'I have gained a lot and helped during exams ... I would like if one day this workshop to be done at my school'. This later participant indicated that he/she would appreciate if this kind of workshops could be extended to his/her school, given that the participants at this NPO (Ikamva Youth) were from various secondary schools around Ebony Park and Ivory Park areas.

\section{Theme 3: improvements in academic performance}

Many researchers have indicated that teaching academic study skills by integrating and embedding these study skills into their curriculum may contribute to learners' academic success. Authors such as Bloxham [21] are of the opinion that study skills are most beneficial when instruction occurs within the content area classroom. Integrating academic study skills into the learners' study material is the only viable option, and for skills teaching to be effective, it must be well anchored and contextualised within the subject specialism [18, 19]. In line with assertions, one participant pointed out, 'Since I have attended the workshop I have improved my history'. Another participant said 'I think I have learnt more and I have improved even my marks in mathematics have improved ... I have applied these skills and they are working'. Another participant further emphasised, 'they are inspiring, pity my marks have changed a bit'. Lastly, another participant said, 'it has impacted on my studies positively ... I would like to attend again'.

It can be inferred that there is a positive correlation between the learners' academic improvement and their self-perception. Self-perception according to [39] is an awareness and perception about oneself in achievement situations. Bong and Skaalvik [40] define self-concept as students' overall feelings of doing well or poorly in a given subject area. In this study, self-perception and self-concept are used interchangeably. In the same vein, [41] opined that learners with high academic self-perception outperform their counterparts academically and master their schoolwork with ease.

\section{Conclusions}

This study sets out to determine whether the academic study skills workshops offered at IY contributed to academic achievement. The empirical evidence gather in the study showed that the least attended workshops by the learners were goal setting, time management and note making. Even though time management was one of the least attended workshops, the respondents' perception in this regard is positive, as some of the learners claimed to have seen the benefits of using their times wisely. The results showed that learners' academic performance 
could improve with appropriate academic support. Study skills workshops can minimise student failure rates, especially when students take advantage of the learning opportunities offered to them. Though this study showed that the results of the majority of the learners have improved as a result of the workshops, several other learners have not applied the study skills learned from goal setting and note making workshops.

Finally, the results of this study mean that in order for academic study skills to contribute to learners' academic performance, they should be integrated and embedded in learners' subject content.

\section{Recommendation}

This study recommends that attendance and participation into the academic study skills should be made mandatory for all the learners at the Ikamva Youth in both Ebony Park and Ivory Park branches. This will ensure that all learners benefit enormously from this programme.

\section{Limitations of the study}

- This study focused only on the learners who attend the Ikamva Youth (Ebony Park and Ivory Park branches) programmes, whereas learners who are doing similar grades in the neighbouring secondary schools were not considered.

- Again, the study was not able to test other variables, which may be contributing to the academic performance of learners, specifically supplementary tutoring which is one of the programmes offered at Ikamva Youth (Ivory Park and Ebony Park branches).

\section{Author details}

Welcome Mswazi Kubeka

Address all correspondence to: wkubeka@uj.ac.za

University of Johannesburg, Johannesburg, South Africa

\section{References}

[1] Osman R, Peterson N. Student engagement with engagement: The case of teacher education students in higher education in South Africa. British Journal of Educational Studies. 2010;58:407 
[2] University of Johannesburg. Policy: Community engagement. Johannesburg: University of Johannesburg; 2014 Available online: https://www.uj.ac.za/about.../policies/Policy\% 20Community\%20Engagement.pdf. [Accessed: December 12, 2017]

[3] Available from: http://ikamvayouth.org/about/history/what-we-do [Accessed: October $27,2017]$

[4] Manuel T. Ikamva Youth's Effective Academic Support is Creating Tomorrows' Leaders (online). Obtained from: http://www.supernews.co.za/ikamvayouths-effective-academic support-is-creating-tomorrows-leaders/

[5] Garikai BW Determinants of Poor Academic Performance; 2010. http://www.articlebase.com/education-articles/determinants-of-poor-academic-performance-3659...pdf [Accessed: May 27, 2013]

[6] Higher Education Quality Committee. Criteria for institutional audits. Pretoria: Council on Higher Education; 2004. Available online: www.uct.ac.za/usr/ipd/HEQC/HEQC_ Acriteria.pdf [Accessed: December 12, 2017]

[7] Wright KN, Williams P, Wright S, Lieber E, Carrasco SR, Gedjeyan H. Ties that bind: Creating and sustaining community-academic partnerships. Gateways: International Journal of Community Research and Engagement. 2011;4:83-99

[8] Dharamsi S, Espinoza N, Cramer C, Amin M, Barinbridge L, Poole G. Nurturing social responsibility through community service-learning: Lessons learned from a pilot project. Medical Teacher. 2010;32(11):905-911. DOI: 10.3109/01421590903434169

[9] Anderson JJ. Community engagement: It is all about relationships. Journal of Community Engagement and Higher Education. 2016;8(1):47-56

[10] Crede' M, Kuneel NR. Study habits, skills and attitudes: The third pillar supporting collegiate academics performance. Albany: University of Albany; 2008. DOI: 10.1111/j.1745-6924.2008.00089.x

[11] Ayodele CS, Adebiyi DR. Study habits as influence of academic performance of university undergraduates in Nigeria. Ado-Ekiti: Ekiti State University; 2013

[12] Hussain A. Effect of guidance services on study attitudes, study habits and academic achievement of secondary school students. Bulletin of Education and Research. 2006; 28(1):35-45

[13] Bliss LB, Mueller RJ. Assessing study behaviors: Findings from a new instrument. Journal of Developmental Education. 1987;11(2):14-18

[14] Anwar E. A correlational study of academic achievement and study habits: Issues and concerns. Excellence. International Journal of Educational Research. 2013;1(2):46-51

[15] Tinto V. Classrooms as communities: Exploring the educational character of student persistence. Journal of Higher Education. 1997;68:599-623 
[16] Khurshid F, Tanveer A, Qasmi FN. Relationship between study habits and academic achievement among hostel living and day scholars' university students. British Journal of Humanities and Social Sciences. 2012;3(2):34-42

[17] Chadha DA. curriculum model for transferable skills development. Engineering Education. 2006;1(1):19-24. Available online: www.tandfonline.com/doi/full/10.11120/ened. 2006.01010019 [Accessed: December 12, 2017]

[18] Atlay M, Harris R. An institutional approach to developing students' transferable skills. Innovations in Education and Training International. 2000;37(1):76-81

[19] Cottrell S. Teaching Study Skills and Supporting Learning. London: Palgrave Study Guides; 2001

[20] Burns T, Sinfield S. Teaching, Learning and Study Skills: A Guide for Tutors. London: Sage; 2004

[21] Bloxham S. Embedding Skills and Employability in Higher Education: An Institutional Curriculum Framework Approach. Cumbria: University of Cumbria; 2004

[22] Richardson J, Robnolt V, Rhodes J. A history of study skills: Not hot, but not forgotten. Reading Improvement. 2010;47(2):111-123

[23] Pressley M, Woloshyn V. Cognitive Strategy Instruction that Really Improves children's Academic Performance. Cambridge: Brookline; 1995

[24] Bowl M. Valuing diversity in the social science curriculum. Learning and Teaching in the Social Sciences. 2005;2(2):121-136

[25] Gettinger M, Seibert JK. Contributions of study skills to academic competence. School Psychology Review. 2002;31(3):350-365

[26] Locke EA, Latham GP. A Theory of Goal Setting and Task Performance. New Jersey: Prentice Hall; 1990

[27] Bailey PD, Onwuegbuzie AJ. The role of study habits in foreign language courses. Assessment and Evaluation in Higher Education. 2002;27:463-473. DOI: 10.1080/ 0260293022000009339

[28] Cohn MC. Helping your teenage student. New York: E.P. Dutton; 1979

[29] Freire P. Pedagogy of the Oppressed. New York: Seabury; 1970

[30] Sharma D. A study of achievement motivation, study habits and academic achievement among secondary school students. Educational quest. An International Journal of Education and Applied Social Sciences. 2012;3(1):17-21

[31] Babbie E, Mouton J. The Practice of Social Research. Cape Town: Oxford University Press; 2001

[32] Opie C. Doing Educational Research. London: Sage Publication; 2004 
[33] Available from: Http://en.wikipedia.org/wiki/Department_of_Basic_Education [Accessed: October 13, 2017]

[34] Turner K, Krenus B, Ireland L, Pointon L. Essential Academic Skills. 2nd ed. Oxford University: Oxford University Press; 2011

[35] Deb S, Strodl E, Sun J. Academic stress, parental stress, anxiety and mental health amongst Indian high school students. International Journal of Psychology and Behavioral Sciences. 2015;5(1):26-34. DOI: 10.5923/j.ijpbs.20150501.04

[36] Sansgiry SS, Bhosle M, Kavita S. Factors that affect academic performance among pharmacy students. American Journal of Pharmaceutical Education. 2006;70(2):26

[37] Miles MB, Huberman MA. Qualitative Data Analysis: A Method Source Book. 3rd ed. Thousand Oak: Sage Publication Inc; 2014

[38] Saldanha J. The Coding Manual for Qualitative Researchers. 2nd ed. Thousand Oak: Sage Publication Inc; 2009

[39] Shavelson RJ, Hubner JJ, Stanton GC. Self-concept: Validation of construct interpreta tions. Review of Educational Research. 1976;46(3):407-411. DOI: 10.3102/00346543046003407

[40] Bong M, Skaalvik EM. Academic self-concept and self-efficacy: How different are they really? Educational Psychology Review. 2003;15(1):1-40. DOI: 10.1023/A:1021302408382

[41] Skaalvik EM, Valas H, Sletta O. Task involvement and ego involvement: Relations with academic achievement, academic self-concept and self-esteem. Scandinavian Journal of Educational Research. 1994;38:231-243

[42] Loock AFS. Promising Practices for Community College Student Success (online). Obtained from: www.inpathways.net/Boylan What\%20Works.pdf [Accessed: December $12,2017]$

[43] Spaull N, Burger R, Burger C, van der Berg S, van Wyk L, Dzivakwi R. Against the Odds: An Evaluation of the Ikamva Youth Programme (online). Obtained from: http://ikamvayouth.org/about/history/what-we-do [Accessed: October 27, 2017] 
